\title{
PERANCANGAN MEDIA IKLAN SEBAGAI PENUNJANG INFORMASI DAN PROMOSI PADA HOTEL SITAMIANG 2 BOGOR
}

\author{
Lusyani Sunarya ${ }^{1}$ \\ Desi Wahyu Kartika Sari ${ }^{2}$ \\ Pajrin Wurika Sahara ${ }^{3}$ \\ ${ }^{1}$ Dosen STMIK Raharja, ${ }^{2,3}$ Mahasiswa STMIK Raharja \\ 1,2,3 Jl.Jendral Sudirman No.40,modern,Tangerang,021-5529692 \\ Email :_lusyani@raharja.infol,desi.wahyu@raharja.info',Wurika.sahara@raharja.info3,
}

\begin{abstract}
ABSTRAK
Perkembangan dunia perhotelan yang makin pesat, menuntut kebutuhan akan informasi dan promosi agar Hotel Sitamiang 2 Bogor semakin diminati oleh customer. Tujuan dari penelitian ini adalah merancang media berbasis audio visual agar dapat menarik dan efektif, terutama dalam penyampaian informasi dan promosi mengenai hal - hal yang berkaitan dengan Hotel Sitamiang 2 Bogor. Permasalahan yang ada yaitu kurangnya media promosi dan informasi yang digunakan pada Hotel Sitamiang 2 Bogor, karena dalam melakukan suatu promosi dan memberikan informasi masih menggunakan media cetak yaitu berupa brosur, untuk itu dibuatlah suatu teknik promosi baru untuk Hotel Sitamiang 2 yaitu dengan menggunakan media iklan yang mampu menginformasikan dan mempromosikan seluruh aset dan keunggulan yang dimiliki perusahaan, dengan harapan akan menarik minat calon customer, menjalin relasi atau kerjasama baik dengan klien perseorangan, klien perusahaan, instansi atau lembaga terkait, dan sebagai media informasi untuk meningkatkan image Hotel Sitamiang 2 agar lebih dikenal lagi di masyarakat khususnya di daerah Bogor dan sekitarnya. Adapun metodologi yang digunakan dalam penelitian ini diantaranya metode analisa permasalahan, metode pengumpulan data, metode analisa perancangan dan metode konsep produksi mavib (KPM) yang meliputi : pre production, production, dan post production. Dengan menggunakan media iklan maka perusahaan akan lebih menarik dalam menyampaikan informasi dan promosi suatu produk dan jasa yang di tawarkan, sehingga perancangan media video iklan Hotel Sitamiang 2 Bogor, diharapkan dapat menjadi solusi dalam pemecahan masalah pada media promosi dan informasinya.
\end{abstract}

Kata Kunci: media iklan, informasi, promosi.

\section{ABSTRACT}

The development of the rapidly growing world of hospitality, demanding the need for information and campaigns to Hotel Sitamiang 2 Bogor increasingly in demand by customers. The aim of this study was to design-based audio-visual media in order to attract and effectively, especially in the delivery of information and promotion about things - things related to Hotel Sitamiang 2 Bogor. Existing problems, namely a lack of media promotion and information used in Hotel Sitamiang 2 Bogor, because in doing a promotion and information are still using the print media in the form of brochures, for that invented a technique new promotion for Sitamiang 2 by using media ads is able to inform and promote all of the assets and advantages of the company, hoping to attract potential customers, establish relationships or good cooperation with the clients

Vol.2 No.1 - Februari 2016 
individual, client company, agency or institution in question, and as a medium of information to enhance the image Hotel Sitamiang 2 to be more known again in society, especially in the area of Bogor and its surroundings. The methodology used in this study include problem analysis methods, data collection methods, methods of analysis of the design and method of production concept mavib (KPM) which includes: pre-production, production and post production. By using advertising media company will be more attractive in conveying information and promotion of products and services on offer, so the design of video media ads Hotel Sitamiang 2 Bogor, is expected to be a solution in solving problems in media promotion and information.

Keywords: media advertising, information, promotion.

\section{PENDAHULUAN}

Pada dasarnya kemajuan
bidang komputerisasi khususnya multimedia kian hari semakin meningkat dan telah mendorong terjadinya arus globalisasi, dimana dalam hal ini perkembangan tersebut tumbuh secara pesat tidak hanya dilihat dari kemampuan dibidang komputer saja, salah satu dari manfaat dan kemajuan teknologi komputer saat ini dapat kita rasakan dalam bidang multimedia audio visual and broadcasting yang memiliki peranan penting dalam dunia teknologi informasi dan berfungsi sebagai media untuk mengolah kreatifitas dan imajinasi menjadi bentuk yang nyata sesuai dengan yang diinginkan. Pengenalan profil perusahaan dan jenis produk yang dipasarkan merupakan proses bisnis perusahaan dengan cara promosi dan informasi sehingga dapat memudahkan perusahaan dikenal oleh calon pelanggan. Untuk itu dengan menggunakan media iklan maka perusahaan akan lebih menarik dalam menyampaikan informasi dan promosi suatu produk dan jasa yang di tawarkan.

Hotel Sitamiang adalah perusahaan yang bergerak di bidang perhotelan, yang didirikan di daerah Bogor, hotel ini didirikan oleh bapak
Dadan Teryana pada tahun 2010. Melihat kemajuan dalam dunia usaha dan untuk meningkatkan peluang bisnis didirikan Hotel Sitamiang 2 sebagai cabang di daerah Bogor, pengurus cabang Hotel Sitamiang 2, berinisiatif lebih meningkatkan kualitas pelayan, fasilitas hotel, melakukan pembaharuan, dan pembuatan sistem yang lebih baik, maka berdirilah Hotel Sitamiang 2 di Bogor.

Saat ini Hotel Sitamiang 2, menggunakan media promosi dan informasi dalam bentuk media cetak yaitu masih berupa brosur hingga sekarang ini, dan melakukan pemasaran dengan memperlihatkan brosur hotel yang berisikan fasilitas hotel dalam bentuk gambar dan tulisan yang sudah rapi dan terorganisir dengan baik, semakin berkembangnya perusahaan dan persaingan yang lebih kompetitif setiap tahunnya, kebutuhan perusahaan akan promosi terus bertambah sesuai dengan perkembangan zaman.

Dalam mengembangkan usahanya saat ini Hotel Sitamiang 2, sangat membutuhkan sarana media penyampaian informasi dan promosi yang mampu menginformasikan dan mempromosikan seluruh aset dan keunggulan yang dimiliki perusahaan, dengan harapan akan 
menarik minat calon customer, menjalin relasi atau kerjasama baik dengan klien perseorangan, klien perusahaan, instansi atau lembaga terkait, dan sebagai media informasi untuk meningkatkan image Hotel Sitamiang 2 agar lebih dikenal lagi di masyarakat khususnya di daerah Bogor dan sekitarnya.

Dari hasil analisa kebutuhan yang dilakukan terhadap Hotel Sitamiang 2 Bogor, perusahaan tersebut membutuhkan media promosi dan informasi yang menarik untuk memperkenalkan seluruh fasilitas dan keunggulan hotel tersebut dan diharapkan melalui perancangan media audio visual dalam bentuk media iklan ini dapat meningkatkan omset perusahaan pada tahun berikutnya.

\section{RUMUSAN MASALAH}

Dalam mengembangkan usahanya saat ini Hotel Sitamiang 2, sangat membutuhkan sarana media penyampaian informasi dan promosi dalam bentuk media iklan yang mampu menginformasikan dan mempromosikan seluruh aset dan keunggulan yang dimiliki perusahaan, dengan harapan akan menarik minat calon customer, menjalin relasi atau kerjasama baik dengan klien perseorangan, klien perusahaan, instansi atau lembaga terkait, dan sebagai media informasi untuk meningkatkan image Hotel Sitamiang 2 agar lebih dikenal lagi di masyarakat khususnya di daerah Bogor dan sekitarnya. Dengan menggunakan media iklan maka perusahaan akan lebih menarik dalam menyampaikan informasi dan promosi suatu produk dan jasa yang di tawarkan. Permasalahan yang terdapat pada penelitian ini adalah kurangnya media promosi dan informasi yang digunakan pada Hotel Sitamiang 2 Bogor, karena dalam melakukan suatu promosi dan memberikan informasi masih menggunakan media cetak berupa brosur yang memiliki keterbatasan dalam memberikan informasi yang detail mengenai ruang lingkup dan keunggulan yang dimiliki perusahaan, maka dari itu dibuatlah suatu teknik promosi baru untuk Hotel Sitamiang 2 yaitu dengan menggunakan media iklan dalam bentuk audio visual.

1. Media dalam bentuk apa yang efektif digunakan dalam memberikan informasi dan promosi tentang Hotel Sitamiang 2?

2. Target seperti apa yang akan dicapai melalui perancangan media promosi dan informasi pada Hotel Sitamiang 2?

3. Bagaimana merancang video iklan yang kreatif dan secara visual dapat menarik perhatian kepada setiap yang melihatnya?

\section{LANDASAN TEORI}

\section{Pengertin Media}

Media adalah beberapa sarana komunikasi (media), yang dipakai untuk menyampaikan dan meyebarluaskan pesan antara lain : media cetak, media elektronik, papan iklan, pos langsung (direct mail). Petunjuk penjualan (point of purchase), selembaran dan kalender [7].

Media adalah segala bentuk yang digunakan untuk menyalurkan informasi. Pengertian media yang diberikan AECT (Association for 
education communication and tecnology) ini menunjukkan bahwa istilah "media" memiliki makna yang sangat umum. ${ }^{[8]}$

Media adalah sarana untuk menyampaikan pesan atau informasi kepada public dengan menggunakan berbagai unsur komunikasi grafis seperti teks atau gambar atau foto. ${ }^{\text {[9] }}$

\section{Pengertian Video}

Video merupakan gabungan gambar - gambar mati yang dibaca berurutan dalam suatu waktu dengan kecepatan tertentu. Gambar-gambar yang digabung tersebut dinamakan frame dan kecepatan pembacaan gambar disebut dengan frame rate, dengan satuan fps (frame per second). Karena dimainkan dalam kecepatan yang tinggi maka tercipta ilusi gerak yang halus, semakin besar nilai frame rate maka akan semakin halus pergerakan yang ditampilkan. Video adalah teknologi untuk menangkap, merekam, memproses, mentransmisikan dan menata ulang gambar bergerak. Biasanya menggunakan film seluloid, sinyal elektronik, atau media digital ${ }^{[10]}$.

Kata video berasal dari kata latin, yang berarti "saya lihat". Video adalah teknologi pemrosesan sinyal elektronik yang mewakilkan gambar bergerak. Aplikasi umum dari teknologi video adalah televisi. Video juga dapat digunakan dalam aplikasi teknik, keilmuan, produksi, dan keamanan. Istilah video juga digunakan sebagai singkatan video tape, perekam video dan pemutar video ${ }^{[4]}$

\section{Konsep Dasar Iklan}

\section{Pengertian Iklan}

Kata iklan berasal dari bahasa Yunani yang artinya adalah menggiring orang pada gagasan. Adapun pengertian iklan secara komprehensif adalah semua bentuk aktivitas untuk menghadirkan dan mempromosikan ide, barang, atau jasa secara non personal yang dibayar oleh sponsor tertentu. Dengan demikian, iklan merupakan suatu proses komunikasi yang bertujuan untuk membujuk atau menggiring orang mengambil tindakan yang menguntungkan bagi pihak pembuat iklan. Sedangkan menurut periklanan adalah bagian dari bauran pemasaran yang secara sederhana dapat didefinisikan sebagai pesan yang menawarkan suatu produk yang ditujukan kepada masyarakat melalui suatu media.

a. Iklan yang efektif

Menyatakan bahwa iklan efektif apabila iklan tersebut mencapai tujuan-

tujuan yang ingin dicapai ole $\mathrm{h}$ pengiklan. Iklan yang efektif adalah iklan yang diciptakan untuk pelanggan yang spesifik, memikirkan dan memahami kebutuhan pelanggan, menekankan pada tindakan spesifik yang harus diambil oleh konsumen serta memahami bahwa orang-orang tidak membeli produk melainkan

membeli keuntungan dari produk tersebut. Selain itu, iklan yang efektif mendapat perhatian dan diingat serta membuat masyarakat bertindak (melakukan pembelian). Dalam konteks periklanan, iklan yang akan disampaikan sebaiknya diramu sedemikian rupa sehingga pesan yang akan 
disampaikan mudah dicerna dan dimengerti oleh masyarakat serta mngandung informasi yang benar. Seandainya pesan suatu iklan dapat terpatri secara mendalam dalam benak konsumen dan konsumen mencermatinya dengan sudut pandang yang benar, maka hal itu berarti hasil kerja mekanisme pasar.

b. Strategi pembuatan iklan yang efektif

Periklanan yang efektif adalah periklanan yang telah mencapai tujuan-tujuan yang ingin dicapai oleh pengiklan, memaparkan bahwa dalam pemilihan strategi yang terbaik akan bergantung pada keadaan produk di dalamnya termasuk keunikan substansial bagi konsumen,kelemahan produk, market share produk, kategori produk (baru atau lama), keadaan pasar, strategi periklanan pesaing, serta market segments yang dapat memunculkan peluang [1].

\section{Pengertian Informasi}

Informasi adalah data yang telah diolah menjadi sebuah bentuk yang lebih berarti bagi penerimanya, dan bermanfaat dalam mengambil sebuah keputusan ${ }^{[6]}$.

Informasi adalah data yang telah diolah menjadi sebuah bentuk yang lebih berarti bagi penerimanya, dan bermanfaat dalam mengambil sebuah keputusan. ${ }^{[3]}$

Informasi adalah data yang diolah menjadi bentuk yang lebih berguna dan lebih berarti bagi penerima dan digunakan untuk mengambil keputusan. ${ }^{[15]}$

\section{Pengertian Promosi}

Promosi merupakan salah satu faktor penentu keberhasilan suatu program pemasaran, Betapapun berkualitasnya suatu produk, bila konsumen belum pernah mendengarnya dan tidak yakin produk itu akan berguna bagi mereka, maka mereka tidak akan pernah membelinya. Pentingnya promosi dapat digambarkan lewat perumpamaan bahwa pemasaran tanpa promosi dapat diibaratkan seorang pria berkaca mata hitam yang dari tempat gelap pada malam kelam mengedipkan matanya pada seorang gadis cantik di kejauhan. Tak seorang pun yang tahu apa yang dilakukan pria tersebut selain dirinya sendiri $^{[11]}$.

pada hakikatnya promosi adalah suatu bentuk komunikasi pemasaran, yang dimaksud dengan komunikasi pemasaran adalah aktivitas pemasaran yang berusaha menyebarkan informasi, mempengaruhi atau membujuk dan mengingatkan pasar sasaran atas perusahaan dan produknya agar bersedia menerima, membeli dan setia pada produk yang ditawarkan perusahaan yang bersangkutan ${ }^{[14]}$.

\section{LITERETURE REVIEW}

1. Penelitian yang dilakukan oleh Richi Setiawan berjudul 2010 "Implementasi Video Iklan Berbasis Animasi 3d Pada SmaIt Alia Tangerang". Promosi yang telah dilakukan oleh SMAIT ALIA TANGERANG adalah melalui media cetak berupa brosur, spanduk, serta banner, 
oleh karenanya sebuah ide baru yang pada akhirnya akan diimplementasikan dengan hasil karya yang mencangkup multimedia, audio visual, and broadcasting. Sebuah iklan profil sebagai media yang dapat dipakai dalam mempersentasikan keunggulan SMA-IT ALIA TANGERANG, iklan profil yang telah dibuat akan dipublikasikan pada acara ALIA fair, PAIS (pesantren alia islamic school), dan ditampilkan pda blog/web SMA-ITALIA TANGERANG ${ }^{[12]}$.

2. Penelitian dilakukan M.Nur Kholis, berjudul 2012 "Perancangan Media Iklan Konsentrasi Multimedia Audio Visual And Broadcasting Pada Jurusan Teknik Informatika Perguruan Tinggi Raharja". Mengenai sarana multimedia sebagai alat komunikasi mempunyai peranan yang sangat penting dalam menginformasikan sesuatu kepada masyarakat, hal ini dinilai sangat komunikatif dan efektif disaat mobilitas manusia yang semakin tinggi sehingga dibutuhkan bentuk media komunikasi yang menarik dan lebih interaktif yang di tujukan kepada masyarakat, dan banyak cara untuk menyampaikan suatu informasi yang di olah dalam bentuk multimedia agar terlihat lebih menarik dalam penyampaiannya. Dalam kesempatan tugas skripsi ini, penulis mengangkat topik permasalahan yang di beri judul perancangan Media Iklan Multimedia Audio Visual And Broadcasting pada jurusan Teknik Informatika Perguruan Tinggi Raharja $^{[6]}$.
3. Penelitian yang dilakukan oleh Muhamad Riyan Surya Nugraha berjudul $2010 \quad$ "Perancangan Media Video Iklan Menggunakan Animasi 3d Di Klinik Usada Nugraha Kabupaten Tangerang".

Pemanfaatan bahan ajar Sistem Informasi Akutansi Berbasis multimedia dapat digunakan sebagai media pembelajaran perancangan pembelajaran berbasis multimedia interaktif pada mata kuliah sistem informasi akutansi dirancang sedemikian rupa berdasarkan kebutuhan dosen dan mahasiswa dengan menggunakan macromedia authorware. Program ini berbasis informasi materi dalam bentuk teks, suara, gambar, video maupun gambar animasi ${ }^{[13]}$.

4. Penelitian yang dilakukan oleh Lima Apriyani berjudul 2012 "Perancangan Video Company Profile Sebagai Media Informasi Dan Promosi Pada Pt. Melia Nature Issn: 1978 8282 Vol.7 No.3 - Mei 2014390 Indonesia". Saat ini, presentasi hanya dilakukan dengan menggunakan media berupa buku dan katalog yang diberikan kepada calon member, namun didalam prosesnya sering terjadi pemahaman yang menyimpang dan tidak fokusnya calon member dalam menerima informasi yang mengakibatkan gagalnya proses presentasi. Karena itu dengan tampilan Animasi yang ada dalam media presentasi akan membuat proses presentasi lebih menarik, dan membantu kebutuhan member dalam memperoleh informasi 
yang lebih detail tentang PT. Melia Nature Indonesia ${ }^{[2]}$.

5. Penelitian yang dilakukan oleh Fitra Ginanjar (2012) dari STMIK Raharja, penelitian ini membahas tentang "Perancangan Media Video Feature Sebagai Penunjang Informasi Dan Promosi Pariwisata Kabupaten Garut Pada Dinas Kebudayaan Dan Pariwisata Kabupaten Garut " penelitian ini dilakukan penulis sebagai media promosi khususnya pada Dinas Kebudayaan dan Pariwisata Kabupaten Garut berdasarkan dari hasil analisa kebutuhan masih sangat kurang, sampai saat ini media yang terdapat pada bagian pemasaran berupa slide dan foto, dalam hal ini dirancang sebuah media audio visual dalam suatu video feature yang dikemas dalam bentuk audio visual yang setiap saat siap untuk dipergunakan oleh pihak pemasaran. Media tersebut diharapkan dapat lebih menarik perhatian wisatawan asing dan masyarakat luas akan adanya media promosi yang berbentuk audio visual pada Dinas Kebudayaan dan Pariwisata Kabupaten Garut ${ }^{[4]}$.

\section{METODOLOGI PENELITIAN}

Pelaksanaan penelitian yang dilakukan, adalah dengan melakukan beberapa metode penelitian diantaranya :

(1)Metode Analisa Permasalahan didapatkan dari hasil interview yang dilakukan dengan stakeholder pada Hotel Sitamiang 2.
(2)Metode pengumpulan data dilakukan dengan cara Observasi, Interview, dan Studi Pustaka.

(3)Metode Analisa Perancangan Media. Perancangan media iklan sebagai penunjang media promosi dan informasi dirancang berdasarkan analisa terhadap media yang telah digunakan pada media sebelumnya, selain dari itu juga terhadap analisa kebutuhan yang diajukan kepada stakeholder, selanjutnya dirancang dengan menggunakan aplikasi program komputer grafis. Media - media yang akan dipergunakan sebagai sarana penujang informasi dan promosi Hotel Sitamiang 2 dirancang dengan menggunakan aplikasi Adobe Premiere Pro CS6, Adobe After Effect CS6 dan Adobe Photoshop CS6. (4) Metode Konsep Produksi Mavib (KPM) yang meliputi : Pre Production, Production, dan Post Production.

\section{PEMBAHASAN}

Tahapan yang dilakukan dalam pembuatan video iklan adalah dengan melakukan konsep dasar media yaitu Preproduction, Production, dan Postproduction. 


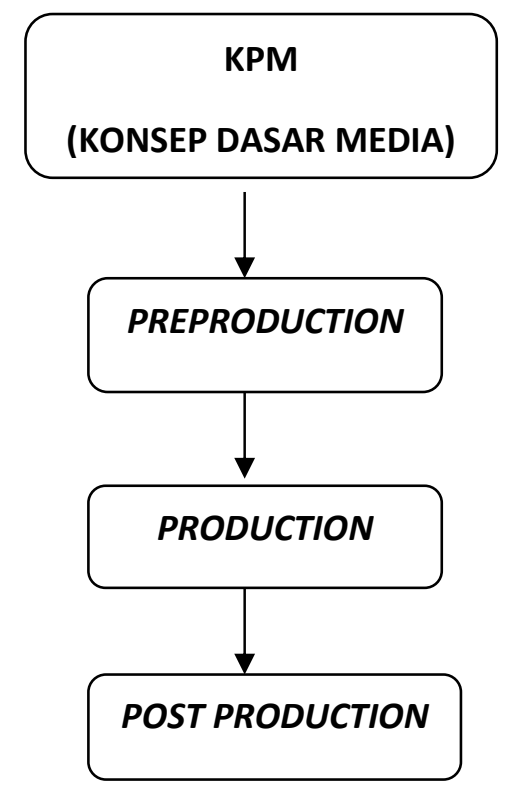

Gambar 1. Konsep Produksi Media (KPM)

\section{Preproduction}

Ada beberapa langkah preproduction dalam pembuatan video iklan pada Hotel Sitamiang 2, dimulai dari observasi lapangan dengan pengumpulan data-data yang diperlukan, kemudian yang dituangkan dalam sebuah ide atau gagasan secara sistematis agar menghasilkan pesan dari media iklan itu sampai kepada penonton, lalu diikuti dengan pembuatan sinopsis, script writting dan storyboard. Dua tahapan terakhir adalah pemilihan dubbing atau crew dan setting alat. Semua tahapan yang ada harus sesuai time schedule yang ditetapkan. Untuk lebih jelasnya di ilustrasikan pada bagan berikut ini :

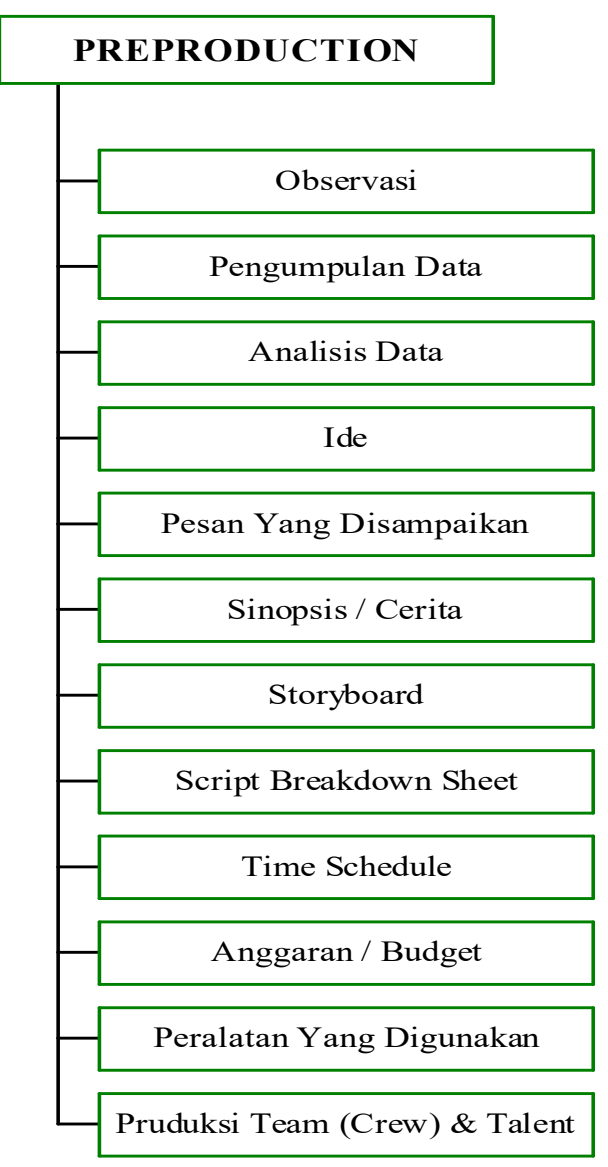

Gambar 2. Preproduction

\section{Pemecahan Masalah}

1. Media promosi sebelumnya hanya menggunakan media cetak berupa brosur saja, kekurangannya adalah informasi yang disampaikan sangat terbatas dan kurang detail. Oleh sebab itu media promosi dan informasi yang dikemas dalam bentuk video iklan sangat diperlukan bagi Hotel Sitamiang 2 , dengan adanya media video iklan tersebut dapat mempromosikan dan menginformasikan perusahaan secara efektif serta dapat meningkatkan suatu image atau citra Hotel Sitamiang 2 kepada masyarakat luas yang melihat video iklan tersebut. 
2. Target yang di harapkan oleh perusahaan melalui media audio visual ini adalah kedepannya agar Hotel Sitamiang semakin diminati para customer tetap dan customer baru dan mengalami peningkatan dalam dunia perhotelan hingga mencapai $50 \%$ dalam peningkatan omset seluruh wilayah Bogor dan luar kota lainnya. Diharapkan juga media iklan ini dapat menjadikan citra atau image Hotel Sitamiang semakin besar dan di kenal oleh masyarakat luas.

3. Dalam merancang sebuah media iklan yang kreatif dan menarik serta dapat memenuhi kebutuhan masyarakat, yaitu dengan membuat sebuah video iklan yang berisikan infomasi-informasi profil, fasilitas, keunggulan, dan promosi mengenai Hotel Sitamiang 2 tersebut, ditunjukan pada hal-hal yang saat ini sedang diminati oleh masyarakat dan halhal kreatifitas yang dapat memenuhi kebutuhan audience diantaranya media tersebut terdapat unsur-unsur Audio, Visual dan Broadcasting, dan disertakan beberapa special efek sehingga tampak lebih menarik agar customer atau masyarakat yang melihatnya tidak bosan terhadap video iklan yang dibuat tersebut.

\section{Sinopsis / Cerita}

Sinopsis / cerita merupakan konsep cerita yang akan dibuat atau mencerminkan alur cerita dari awal sampai akhir adegan. Sinopsis perancangan video iklan sebagai penunjang informasi dan promosi pada Hotel Sitamiang ini adalah :
"Pada tahun 2010 berdirilah perusahaan yang bergerak di bidang perhotelan yang bernama Hotel Sitamiang 2 terletak di Jl. Raya Puncak Km.82 Cibeureum CisaruaBogor. Hotel yang bernuansa alam dengan suasana pemandangan yang sejuk dan memiliki arsitektur bangunan yang di buat mengikuti suasana pedesaan menambah daya tarik untuk para customer yang ingin menginap di Hotel Sitamiang 2 tersebut. Hotel Sitamiang 2 memiliki berbagai fasilitas untuk melengkapi kegiatan para customer diantaranya adalah fasilitas restaurant dengan menu yang setiap harinya berbeda dan masih mensajikan makanan daerah yang dihidangkan dengan cara prasmanan agar customer bisa bebas memilih menu yang di suka, fasilitas ruang rapat yang berguna untuk para perusahaan yang ingin mengadakan kegiatan rapat di luar kantor, fasilitas selanjutnya kamar tidur dengan kamar tidur yang di buat minimalis memberikan kesan hangat bagi para customer yang menginap, fasilitas kolam renang yang terletak tidak jauh dari kamarkamar customer menginap. Hotel Sitamiang 2 juga memiliki beberapa tipe Hotel yang memiliki arsitektur berbeda-beda dengan suasana yang berbeda pula yang di buat sesuai dengan kebutuhan customer yang ingin menginap di antaranya Mandala, Zambrud, Kalimaya, Mirah, Delima dan Shappire, selain fasilitas-fasilitas ini Hotel Sitamiang 2 Bogor juga memiliki taman bermain yang aman dan nyaman yang dibuat khusus untuk anak-anak agar tidak bosan selagi tidak ada kegiatan di dalam Hotel dan fasilitas Bungalow yang di buat untuk para customer yang ingin menginap dengan jumlah keluarga yang cukup

Vol.2 No.1 - Februari 2016 
banyak dengan fasilitas berbeda yang sudah di sediakan khusus untuk setiap customer yang ingin menginap menggunakan Bungalow. Hotel Sitamiang 2 di bangun khusus untuk customer yang ingin lebih menikmati suasana alam"

Pembuatan Storyboard

Tabel 1. Storyboard

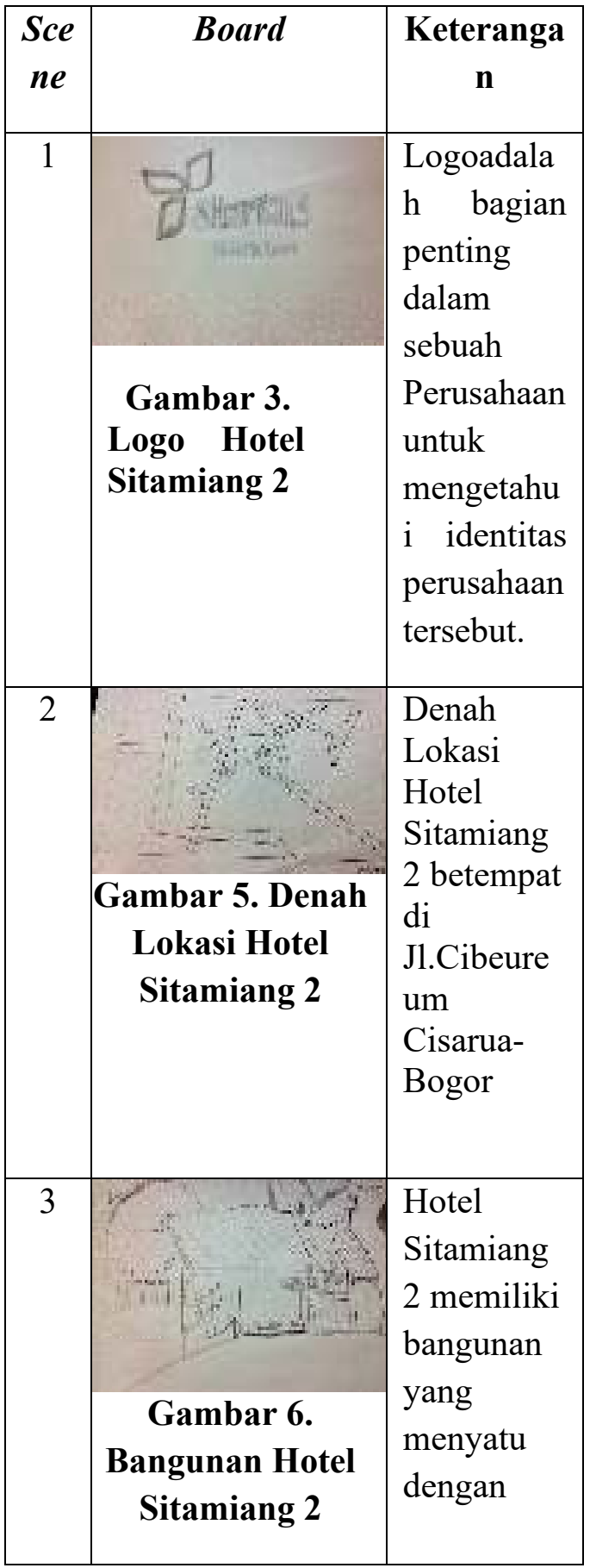

\begin{tabular}{|c|c|c|}
\hline & & alam// \\
\hline 4 & $\begin{array}{c}\text { Gambar 7. Ruang } \\
\text { Rapat Hotel } \\
\text { Sitamiang } 2\end{array}$ & $\begin{array}{l}\text { Fasilitas } \\
\text { ruang rapat } \\
\text { yang } \\
\text { terdapat di } \\
\text { Hotel } \\
\text { Sitamiang } \\
2 \\
\text { membantu } \\
\text { perusahaan } \\
\text { yang ingin } \\
\text { mengadaka } \\
\text { n rapat di } \\
\text { luar kota// }\end{array}$ \\
\hline 5 & $\begin{array}{c}\text { Gambar } 8 . \\
\text { Kamar Tidur } \\
\text { Hotel Sitamiang }\end{array}$ & $\begin{array}{l}\text { Dengan } \\
\text { kamar } \\
\text { tidur yang } \\
\text { dibuat } \\
\text { dengan } \\
\text { bentuk } \\
\text { minimalis } \\
\text { menbah } \\
\text { kesan } \\
\text { hangat } \\
\text { untuk para } \\
\text { customer } \\
\text { yang } \\
\text { menginap/ }\end{array}$ \\
\hline 6 & $\begin{array}{c}\text { Gambar } 9 \text { Kolam } \\
\text { Renang Hotel } \\
\text { Sitamiang } 2\end{array}$ & $\begin{array}{l}\text { Hotel } \\
\text { Sitamiang } \\
2 \text { juga } \\
\text { memiliki } \\
\text { fasilitas } \\
\text { kolam } \\
\text { renang } \\
\text { yang letak } \\
\text { nya tidak } \\
\text { jauh dari } \\
\text { kamar para }\end{array}$ \\
\hline
\end{tabular}

Vol.2 No.1 - Februari 2016 


\begin{tabular}{|c|c|c|}
\hline & & customer/ \\
\hline 7 & $\begin{array}{c}\text { Gambar } 10 \\
\text { Bungalow Hotel } \\
\text { Sitamiang } 2\end{array}$ & $\begin{array}{l}\text { Bungalow } \\
\text { bergunaa } \\
\text { untuk para } \\
\text { customer } \\
\text { yang ingin } \\
\text { menginap } \\
\text { dengan } \\
\text { jmlah } \\
\text { keluarga } \\
\text { yang } \\
\text { cukup } \\
\text { banyaak/ }\end{array}$ \\
\hline 8 & \begin{tabular}{|c|} 
Gambar 11. \\
Fasilitas Hiburan \\
Hotel Sitamiang 2
\end{tabular} & $\begin{array}{l}\text { Fasilitas } \\
\text { hiburan } \\
\text { yang } \\
\text { berguna } \\
\text { untuk } \\
\text { memanjak } \\
\text { an } \\
\text { customer/ }\end{array}$ \\
\hline 9 & $\begin{array}{c}\text { Gambar } 12 \\
\text { Bummper Closing } \\
\text { Hotel Sitamiang } 2\end{array}$ & $\begin{array}{l}\text { Bummper } \\
\text { Closing } \\
\text { Hotel } \\
\text { Sitamiang } \\
2\end{array}$ \\
\hline
\end{tabular}

Storyboard adalah rancangan berupa sket gambar yang dilengkapi dengan petunjuk atau catatan pengambilan gambar untuk kebutuhan pembuatan video. Selama proses praproduksi, perencanaan yang berhubungan dengan visualisasi yang akan dibuat membutuhkan storyboard sebagai media bantuannya.

\section{Production}

Production

adalah berkerjasama antara editor dan crew untuk pewujudan dari naskah, storyboard dan tepatnya time schedule yang telah dibuat. Ditahap ini pengambilan gambar atau shooting dibuat. Dari pengambilan gambar di lokasi yang sesuai hingga selesainya take script time schedule. Pada tahapan ini pengolahan sampai mixing multimedia, audio, visual dan broadcasting dibuat untuk menghasilkan karya yang berkualitas.

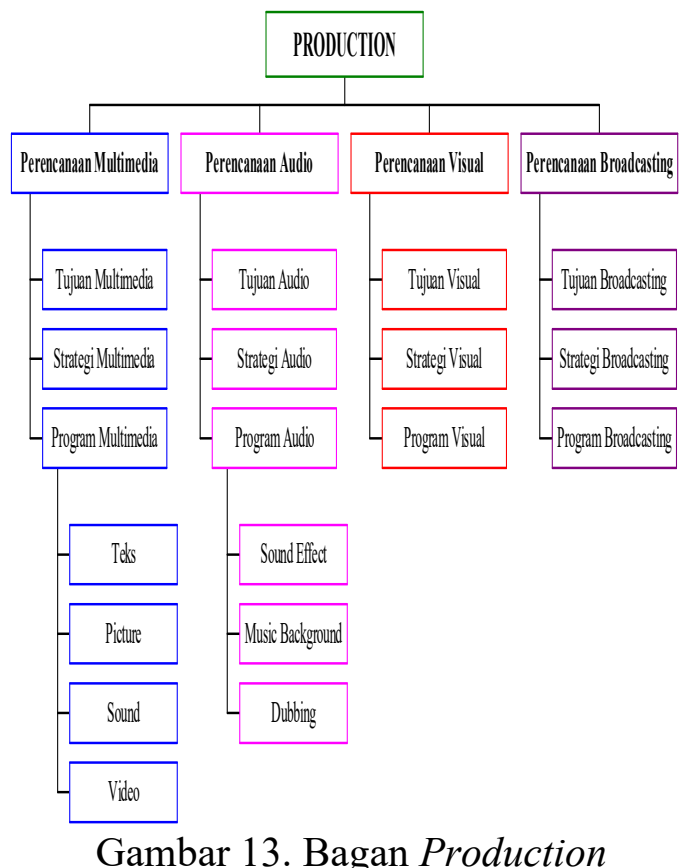

Postproduction

Pada tahapan ini hampir sama dengan perencanaan Broadcasting namun yang membedakan Postproduction pendistribusiannya lebih luas. Dengan berbagai format video sehingga bisa di tampilkan dengan leluasa. 


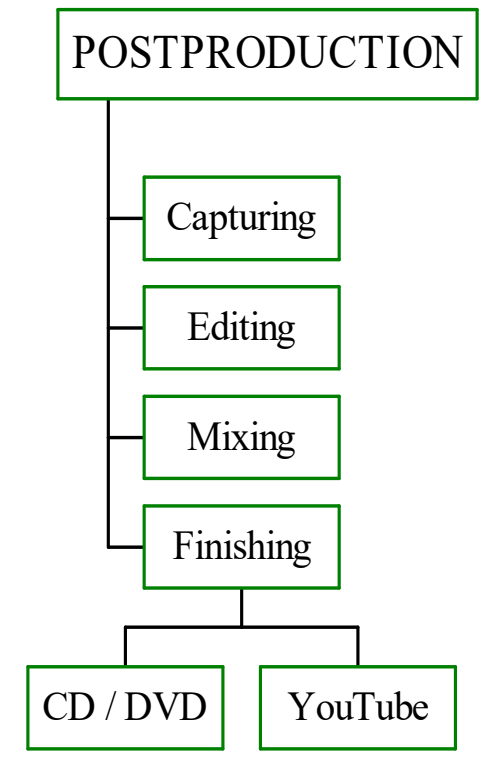

Gambar 14. Bagan postproduction

\section{Tampilan Isi}

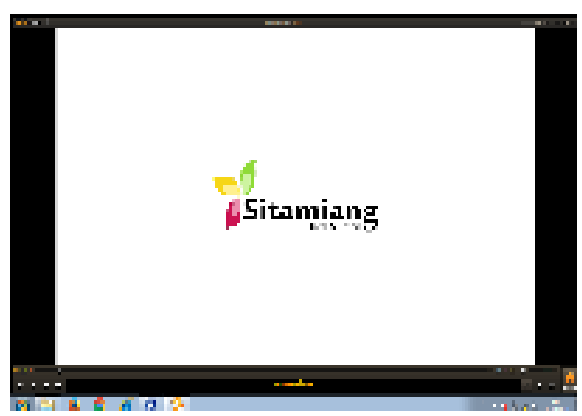

Gambar 15. Logo Hotel Sitamiang 2

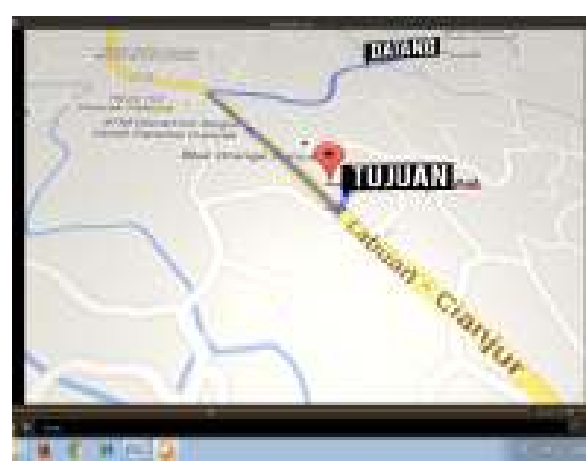

Gambar 16. Denah Lokasi Hotel Sitamiang 2

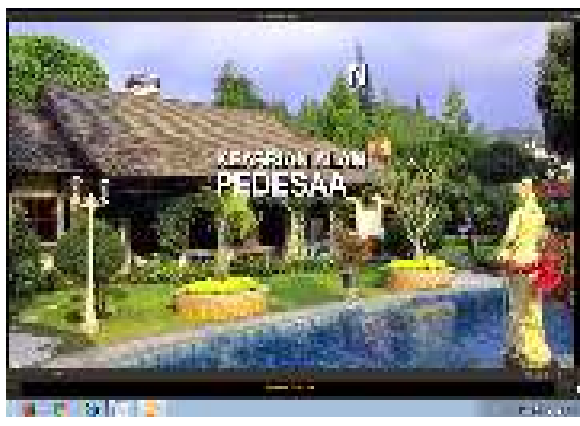

Gambar 17. Bangunan Hotel Sitamiang 2

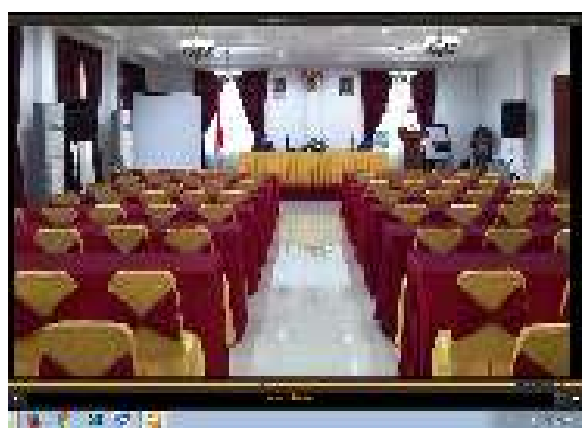

Gambar 18. Ruang Rapat Hotel Sitamiang 2

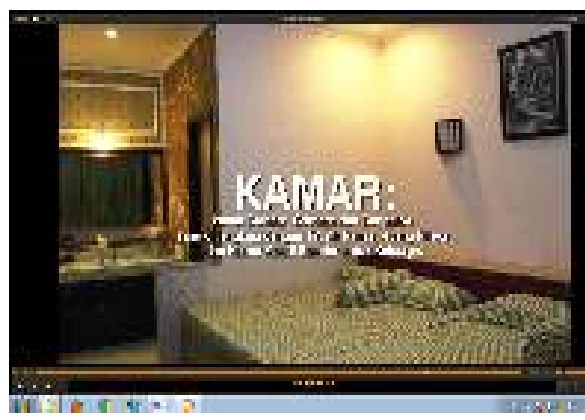

Gambar 19. Kamar Tidur Hotel Sitamiang

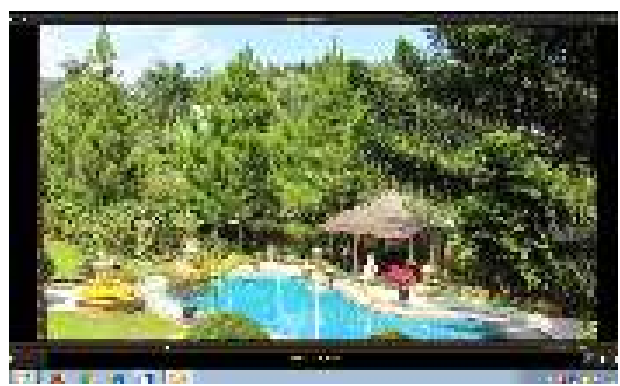

Gambar 20. Kolam Renang Hotel Sitamiang 2 


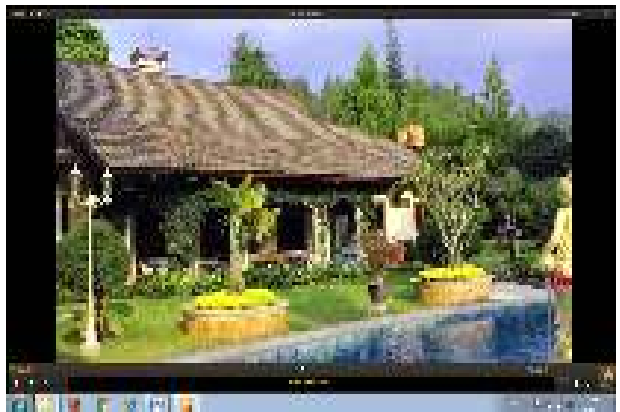

Gambar 21. Bungalow Hotel Sitamiang 2

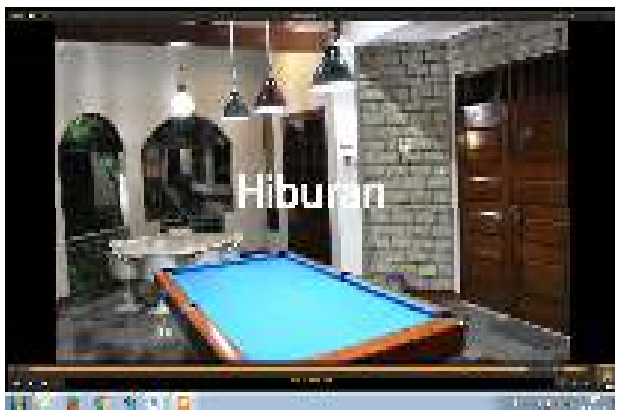

Gambar 22. Fasilitas Hiburan Hotel Sitamiang 2

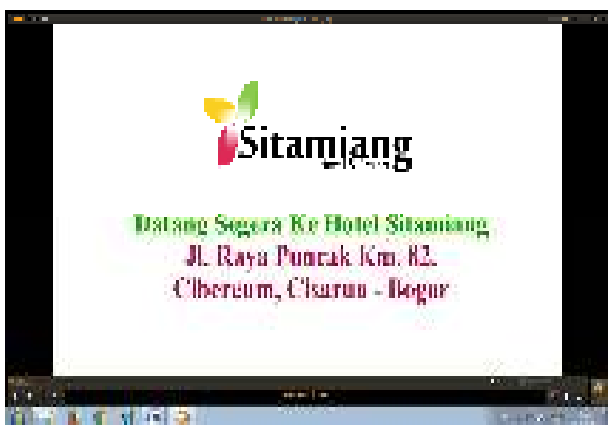

Gambar 23. Bummper Closing Hotel Sitamiang 2

Tampilan isi mengambil dari profile Hotel Sitamiang 2 yaitu meliputi keunggulan, fasilitasfasilitas dan memaparkan segala sesuatu tentang Hotel Sitamiang 2.

\section{KESIMPULAN}

Dalam mempromosikan dan menginformasikan ruang lingkup serta keunggulan Hotel Sitamiang 2 Bogor adalah dengan merancang media iklan. Dalam pembuatan sebuah media audio visual dalam bentuk media iklan yang baik harus memperhatikan faktor-faktor yang berhubungan dengan perusahaan yang bersangkutan, mulai dari tahap preproduction, production, dan postproduction. Hal ini bertujuan untuk memperkuat pemasaran (marketing)dalam menginformasikan dan mempromosikan Hotel Sitamiang 2 Bogor. Dalam merancang sebuah media iklan yang kreatif dan menarik serta dapat memenuhi kebutuhan masyarakat, yaitu dengan membuat sebuah video iklan yang berisikan infomasiinformasi profil, fasilitas, keunggulan, dan promosi mengenai Hotel Sitamiang 2 tersebut, ditunjukan pada hal-hal yang saat ini sedang diminati oleh masyarakat dan hal-hal kreatifitas yang dapat memenuhi kebutuhan audience diantaranya media tersebut terdapat unsur-unsur audio, visual dan broadcasting, dan disertakan beberapa special efek sehingga tampak lebih menarik.

Target yang di harapkan oleh perusahaan melalui media iklan ini adalah kedepannya agar Hotel Sitamiang 2 Bogor semakin diminati para customer tetap dan customer baru dan mengalami peningkatan omset seluruh wilayah Bogor dan luar kota lainnya. Diharapkan juga media iklan ini dapat menjadikan citra atau image Hotel Sitamiang semakin besar dan di kenal oleh masyarakat luas.

\section{DAFTAR PUSTAKA}

[1] Ayuningtyas, Melvy.2011. Edit Video Dengan Adobe 
Premiere CS6,

Bekasi:Dunia Komputer.

[2] Apriyani,Lima.2012.

Perancangan Company

Profile Sebagai Media

Informasi dan Promosi

Pada PT.Melia Nature

ISSN: 1978 - 8282 Vol.7

No.3 - Mei 2014390

INDONESIA. Tangerang :

Perguruan Tinggi Raharja.

[3] Dewi Immaniar Desrianti dkk, dalam jurnal CCIT Vol. 5 No. 2

[4] Ginanjar, Fitrah .2012. Perancangan Media Video Feature Sebagai Penunjang Iformasi Dan Promosi Parawisata Kabupaten Garut Pada Dinas Kebudayaan Dan Parawisata Kabupaten Garut.Tangerang : Perguruan Tinggi Raharja.

[5] Komala,

Lukiati.2011.Produksi

promosi pemasaran aktivitas.Bandung.

[6] Kholis Nur Muhamad. 2012. Perancangan Media Iklan Konsentrasi Multimedia Audio Visual and Broadcasting Pada Jurusan Teknik Informatika Perguruan Tinggi Raharja. Tangerang : Perguruan Tinggi Raharja.

[7] Maimunah, 2012. Media Company Profile Sebagai Sarana Penunjang Informasi Dan Promosi. Tangerang : Jurnal CCIT (Vol.5 No.3).

[8] Maimunah dkk, Jurnal CCIT Vol. 5 No. 3

[9] Maimunah dkk, Jurnal CCIT Vol.5 No.3
[10] Raharja, Untung, dkk. 2010. Audio Visual as One The Teaching Resources On Ileaning. Tangerang : Jurnal CCIT (Vol.5 No. 2).

[11 ]Rhenald, Khasali, 2010 Manajemen Periklanan Konsep dan Aplikasinya di Indonesia. Jakarta: Pustaka Utama Grafiti.

[12] Setiawan, Richi berjudul 2010 "Implementasi Video Iklan Berbasis Animasi 3d Pada Sma-It Alia Tangerang".

[13] Surya Riyan Muhamad. 2010. Perancangan Media Video Iklan Menggunakan Animasi 3D DI Klinik Usada Nugraha Kabupaten Tangerang. Tangerang : Perguruan Tinggi Raharja.

[14] Usmara, 2012. Media Promosi, Jakarta: Salemba Empat.

Vol.2 No.1 - Februari 2016 